\title{
Advanced Maternal Age and the Frequency of Pre-Eclampsia - A Single-Center Cross Sectional Study from Saudi Arabia
}

\author{
Ahmed Abu-Zaid ${ }^{1}$, Mohammed Alomari², Majed Al-Hayani ${ }^{3}$, Abdulrahman Bazi ${ }^{4}$, Asim Almazmomy ${ }^{5}$ \\ Abdulaziz Alsaegh 6 , Hattan Alshawkani ${ }^{7}$, Ashraf Radwan ${ }^{8}$
}

\begin{abstract}
${ }^{1}$ Department of Medicine, Alfaisal University, Riyadh, Saudi Arabia. ${ }^{2}$ Department of Medicine, King Abdulaziz University, Rabigh, Saudi Arabia. ${ }^{3}$ Department of Medicine, King Abdulaziz University, Rabigh, Saudi Arabia. ${ }^{4}$ Department of Medicine, King Abdulaziz University, Rabigh, Saudi Arabia. ${ }^{5}$ Department of Medicine, King Abdulaziz University, Rabigh, Saudi Arabia. ${ }^{6}$ Department of Medicine, King Abdulaziz University, Rabigh, Saudi Arabia. ${ }^{7}$ Department of Medicine, Umm Al-Quraa University, Makkah, Saudi Arabia. ${ }^{8}$ Department of Obstetrics and Gynecology, King Abdulaziz University, Rabigh, Saudi Arabia.
\end{abstract}

\section{ABSTRACT}

\section{BACKGROUND}

Pregnancy at advanced maternal age ( $\geq 35$ years) has become very common worldwide. Pre-eclampsia (PE) is a serious complication of hypertensive pregnancy that is associated with considerable morbidity and mortality to both the mother and foetus/newborn. This research aimed to inspect the prevalence of PE in a single hospital located in Jeddah, Saudi Arabia, and examine the influence of advanced maternal age ( $\geq 35$ years) on the occurrence of PE in singleton deliveries.

\section{METHODS}

A retrospective study (January 2011 to December 2018) was carried out at King Abdulaziz University Hospital (KAUH), located in Jeddah, Saudi Arabia. Categorical variables were evaluated with $\chi^{2}$ test. Odds ratio (OR) with $95 \%$ confidence intervals $(95 \% \mathrm{CI})$ was used to estimate the comparative risk of developing PE (the outcome variable) according to the maternal age (the exposure variable) at the time of pregnancy.

\section{RESULTS}

During the study period, 3942 singleton deliveries occurred at KAUH. The demographic characteristics (age and PE) of the study population are summarized in Table 1. Overall, there were 2426 deliveries with a maternal age $<34$ years $(61.5 \%)$, whereas there were 1516 deliveries with a maternal age $\geq 35$ years (38.5\%). Only 167 deliveries had a diagnosis of PE, thus yielding an overall prevalence of $4.2 \%$ in this retrospective study. The percentages of PE cases in patients with maternal age $<34$ years and $\geq 35$ years were $3.7 \%$ and $5.1 \%$, respectively. Two-tailed Chi-square test of independence showed that there was a statistical significance between advanced maternal age and occurrence of PE $(\mathrm{p}=0.02)$. To examine the comparative risk of developing PE with relation to the maternal age, an OR analysis showed that patients with advanced maternal age ( $\geq 35$ years) were 1.4 times more likely to develop PE during gestation when compared to patients with $<34$ years, and this comparative risk was substantial (OR: 1.4, 95\% CI: 1.1-1.9, p=0.03).

\section{CONCLUSIONS}

The low prevalence of PE (3.9\%) in our study was largely in agreement with the published regional and international figures. Advanced maternal age ( $\geq 35$ years) is a statistically significant factor for developing PE during pregnancy.

\section{KEY WORDS}

Incidence, Prevalence, Pre-Eclampsia, Advanced Maternal Age, Saudi Arabia

\author{
Corresponding Author: \\ Ahmed Abu-Zaid, \\ Department of Pharmacology, \\ College of Graduate Health Sciences, \\ University of Tennessee Health Science \\ Center, Memphis, Tennessee, USA. \\ E-mail:aabuzaid@live.com
}

DOI: 10.14260/jemds/2020/592

How to Cite This Article:

Abu-Zaid A, Alomari M, Al-Hayani M, et al. Advanced maternal age and the frequency of pre-eclampsia- a single-center crosssectional study from Saudi Arabia. J. Evolution Med. Dent. Sci. 2020;9(37):27262729, DOI: $10.14260 /$ jemds/2020/592

Submission 07-05-2020,

Peer Review 04-08-2020,

Acceptance 11-08-2020,

Published 14-09-2020.

Copyright (C) 2020 JEMDS. This is an open access article distributed under Creative Commons Attribution License [Attribution 4.0 International (CC BY 4.0)] 


\section{BACKGROUND}

Pregnancy at advanced maternal age has become very common worldwide, including the developed and developing countries over the past few decades.[1-3] Reasons for delayed childbearing and motherhood are multifactorial and may be attributable to a wide array of personal, cultural, social, biological and economic factors. ${ }^{4]}$ The literature is conflicted on the age cut-off for advanced maternal age; however, the most commonly accepted consensus for advanced maternal age is 35 years or older.[5] Others specify "very" advanced maternal age as 40 years or older, ${ }^{[6]}$ or 45 years or older.[7,8]

Pregnancy at advanced maternal age ( $\geq 35$ years) is hardly ever without threats to the mother and foetus/newborn.[3] Accumulating evidence from high-quality systematic reviews and meta-analyses of several studies have established links between advanced maternal age and adverse pregnancy results. Such outcomes are enormous and comprise foetal loss (for example, miscarriage and still-birth), hypertensive disorders (for example, eclampsia, pre-eclampsia (PE) and gestational hypertension), abnormal newborn growth, placental abnormalities (for example, placenta previa and placenta abruption), preterm labour (spontaneous or iatrogenic), gestational diabetes mellitus and Caesarean section (elective or emergency).[3,9-14]

$\mathrm{PE}$ is a common hypertensive condition of pregnancy worldwide. PE is characterized by the presence of new-onset hypertension and proteinuria plus/minus multi-organ dysfunction taking place after 20 weeks of gestation. ${ }^{[15]}$ It is regarded as a serious complication of pregnancy that is associated with considerable morbidity and mortality to both the mother and foetus/newborn.[15] Positive risk factors for PE are abundant and include, but not limited to, advanced maternal age, family history of PE, nulliparity, multiple pregnancy, molar pregnancy and maternal comorbidities (for example, diabetes mellitus, obesity, chronic hypertension and chronic kidney disease).[16]

Advanced maternal age ( $\geq 35$ years) constitutes a substantial influential factor implicated in adverse pregnancy outcomes generally, ${ }^{[2]}$ and in PE specifically. $[3,10,16,17]$ Thus, the knowledge of this population-based risk factor is of great value in the childbearing decision-making for both patients (that is, the mothers with advanced maternal age) and the managing physicians.

To the best of our knowledge, from Saudi Arabia, there is a few number of studies which endeavoured to estimate the prevalence of PE among pregnant women.[2,18-23] Moreover, only half of these studies attempted to directly inspect the link between advanced maternal age and the occurrence of PE. $[2,8,20]$ Such epidemiological studies are warranted to withdraw concrete population-specific conclusions pertaining to the prevalence of PE in Saudi Arabia and its relationship to advanced maternal age.

Thus, the task of this research is two folds: (i) to estimate the frequency of PE in a single hospital located in the Jeddah, Saudi Arabia, and (ii) to examine the influence of advanced maternal age ( $\geq 35$ years) on the frequency of PE.

\section{METHODS}

The cross-sectional study was carried out at King Abdulaziz University Hospital (KAUH), located in Jeddah, Saudi Arabia. The research procedure was cleared by the Research Ethics Board (Reference: 361-19).

From 01-January-2011 to 31-December-2018, the number of all singleton deliveries was identified. Afterward, the respective electronic medical records were retrospectively analysed for two demographical data including maternal age and the occurrence of PE.

The diagnosis of PE was established in line with the guidelines of ISSHP, which stands for the International Society for the Study of Hypertension in Pregnancy.[24]

The research inclusion criteria consisted of: (i) maternal age of greater than or equal to 18 years, (ii) singleton pregnancy, and (iii) confirmed diagnosis of PE. The research exclusion criteria consisted of: (i) maternal age less than or equal to17 years, (b) non-singleton pregnancy, and (iii) incomplete data about maternal age and occurrence of PE.

The primary two tasks of this research are: (i) to explore the prevalence of $\mathrm{PE}$, and (ii) to scrutinize the link between advanced maternal age ( $\geq 35$ years) and frequency of PE. To that end, pregnant women were dichotomized into two sets of patients: (i) $<34$ years, and (ii) $\geq 35$ years. In this study, the age cut-off for advanced maternal age of 35 years was in line with the most commonly accepted consensus for advanced maternal age. [5]

Data were analysed using the SPSS software. A p value less than 0.05 was counted as significant statistically. $\chi^{2}$ test was used to compare categorical variables. Odds ratios (OR) with $95 \%$ confidence intervals $(95 \% \mathrm{CI})$ was used to estimate the comparative risk of developing PE (the outcome variable) according to the maternal age (the exposure variable) at the time of pregnancy.

\section{RESULTS}

During the study period, 3942 singleton deliveries occurred at KAUH. Overall, there were 2426 deliveries with a maternal age $<34$ years (61.5\%), whereas there were 1516 deliveries with a maternal age $\geq 35$ years (38.5\%). Only 167 deliveries had a diagnosis of PE, thus yielding an overall prevalence of $4.2 \%$ in this retrospective study. The percentages of $\mathrm{PE}$ cases in patients with maternal age $<34$ years and $\geq 35$ years were $3.7 \%$ and $5.1 \%$, respectively.

Two-tailed Chi-square test of independence showed that there was a statistical significance between advanced maternal age and occurrence of PE ( $\mathrm{p}=0.02)$. To examine the comparative risk of developing PE (the outcome variable) with relation to the maternal age (the exposure variable), an odds ratio (OR) analysis showed that patients with advanced maternal age ( $\geq 35$ years) were 1.4 times more likely to develop PE during gestation when compared to patients with $<34$ years, and this comparative risk was substantial (OR: 1.4, 95\% CI: 1.1-1.9, $\mathrm{p}=0.03$ ). 


\begin{tabular}{|c|c|c|c|c|}
\hline References & Authors & Year & $\begin{array}{c}\text { Region of } \\
\text { Saudi Arabia }\end{array}$ & $\begin{array}{c}\text { Prevalence } \\
\text { of Pre-Eclampsia }\end{array}$ \\
\hline [19] & Al-Ghamdi et al. & 1999 & Northwest & $1.9 \%^{*}$ \\
\hline [18] & Lawoyin et al. & 1996 & Northwest & $2.8 \%$ \\
\hline [20] & Al-Mulhim et al. & 2003 & East & $2.5 \%$ \\
\hline [21] & Sobande et al. & 2007 & Southwest & $0.9 \% \dagger$ \\
\hline [22] & Wahabi et al. & 2016 & Central & $1.1 \%$ \\
\hline [2] & Fayed et al. & 2017 & Central & $1.1 \%$ \\
\hline$[23]$ & Subki et al. & 2018 & West & $1.3 \%$ \\
\hline Present study & Abu-Zaid et al. & 2020 & West & $4.3 \%$ \\
\hline \multicolumn{5}{|c|}{$\begin{array}{c}\text { Table 1. Studies that Reported the Frequency of } \\
\text { Pre-Eclampsia in Saudi Arabia }\end{array}$} \\
\hline $\begin{array}{l}\text { * Frequency } \\
\text { † Frequency }\end{array}$ & $\begin{array}{l}\text { te includes the co } \\
\text { te includes only t }\end{array}$ & $\begin{array}{l}\text { the freq } \\
\text { the }\end{array}$ & $\begin{array}{l}\text { frequency of pre- } \\
\text { uency of "severe" }\end{array}$ & $\begin{array}{l}\text { clampsia and eclampsia } \\
\text { re-eclampsia. }\end{array}$ \\
\hline
\end{tabular}

\section{DISCUSSION}

Hypertensive disorders of pregnancy (HDP) are commonly encountered in the antenatal clinics, and they are estimated to complicate $10 \%$ of all gestations. ${ }^{[25]}$ HDP comprise four subcategories, namely, gestational hypertension, $\mathrm{PE}$, chronic hypertension and chronic hypertension with superimposed PE.[15]

PE carries on to be a chief root of morbidity and mortality to pregnant women and their newborn.[15] The precise underlying pathogenesis of PE remains unknown.[26] Nevertheless, contemporarily, PE is largely understood as a disorder of placental insufficiency and generalized endothelial dysfunction.[26] Early-onset/'placental' and late-onset/ 'maternal' PE happen before 34 and after 34 weeks of gestation, respectively.[27]

Worldwide, the estimated incidence of PE is 4-5\%.[28] Our study demonstrated that the incidence of PE was $4.2 \%$. This figure was in accordance with the published literature from Saudi Arabia (Table 1).[2,18-23] The numerical differences observed in the incidence rates of PE can be ascribed to several factors, such as the differences in the populations studied and heterogeneity in the study design. To elaborate, Al-Ghamdi et al.[19] found that the frequency of both PE and eclampsia was $1.9 \%$ without differentiating the specific proportions of each disorder in their study. Contrariwise, Sobande and friends.[21] reported only the incidence of patients who were diagnosed with 'severe' PE which amounted to $0.9 \%$.

In our study, twin pregnancies were excluded from the study analysis for two reasons. First, we wanted to have a uniform (controlled) study population with regard to singleton pregnancy versus non-singleton pregnancy. Second, twin pregnancies have been shown to intrinsically increase the risk of PE by three to four folds when compared with singleton pregnancies, ${ }^{[29]}$ and this could have indirectly influenced the relationship between advanced maternal age and occurrence of PE in our study.

Population-based data from Saudi Arabia on how maternal age relates to adverse pregnancy outcomes, specifically PE, are sparse. $[2,18,20]$ Our research portrayed advanced maternal age ( $\geq 35$ years) was accompanied by a higher incidence rate of PE. Our finding is in agreement with the vast body of the published literature in which there is a positive correlation between advanced maternal age and the incidence of PE. $[3,5,10,17,30]$ The characteristics of PE such as, mean systolic blood pressure, gestational age and etcetera were not the primary focus of the study. Similarly, the maternal and foetal outcomes of PE were not the primary goals of the present study. Nevertheless, overall, our study, specifically, enriches the regional and international literature by providing additional data about the incidence of PE and its relationship to advanced maternal age. In addition, the findings of the present study have significant implications in clinical practice, one of which is that advanced maternal age is associated with a higher likelihood of developing PE, which should be properly counselled during antenatal visits to inform the best decisionmaking of childbearing.

Our study has several limitations which include the singlecenter experience, retrospective study design and the small sample size of patients with advanced maternal age, which may have influenced the power of statistical analysis. Additional limitations include the lack of reporting maternal and foetal outcomes of PE, which will be addressed extensively in a forthcoming research study. Moreover, other known risk factors for PE (for example, twin pregnancy, first pregnancy and family history of PE) will be investigated. Lastly, it should be noted that in our study we did not adjust (control) for other confounding variables (for example, preexisting chronic conditions, smoking, obesity, first pregnancy, history of previous $\mathrm{PE}$, assisted reproductive technology and etcetera) which could have impacted the relationship between the advanced maternal age and incidence of PE.

\section{CONCLUSIONS}

In our retrospective cross-sectional study, the low prevalence of PE (4.2\%) mirrored the published regional and international figures. Moreover, our research showed that advanced maternal age ( $\geq 35$ years) constituted a substantial demographical factor implicated in developing PE. Counseling women with advanced maternal age about PE during antenatal visits should never be overlooked. More prospective, largesized, and multi-center studies are warranted to gauge the national incidence rate of $\mathrm{PE}$ and its adverse pregnancy outcomes in the Saudi population in order to formulate healthcare policies.

Financial or Other Competing Interests: None.

\section{REFERENCES}

[1] Molina-Garcia L, Hidalgo-Ruiz M, Cocera-Ruiz EM, et al. The delay of motherhood: reasons, determinants, time used to achieve pregnancy, and maternal anxiety level. PLoS One 2019;14(12):e0227063.

[2] Fayed AA, Wahabi H, Mamdouh H, et al. Demographic profile and pregnancy outcomes of adolescents and older mothers in Saudi Arabia: analysis from Riyadh Mother (RAHMA) and Baby cohort study. BMJ Open 2017;7(9):e016501.

[3] Pinheiro RL, Areia AL, Mota Pinto A, et al. Advanced maternal age: adverse outcomes of pregnancy, a metaanalysis. Acta Med Port 2019;32(3):219-26.

[4] Schmidt L, Sobotka T, Bentzen JG, et al. Demographic and medical consequences of the postponement of parenthood. Hum Reprod Update 2012;18(1):29-43. 
[5] Khalil A, Syngelaki A, Maiz N, et al. Maternal age and adverse pregnancy outcome: a cohort study. Ultrasound Obstet Gynecol 2013;42(6):634-43.

[6] Traisrisilp K, Tongsong T. Pregnancy outcomes of mothers with very advanced maternal age (40 years or more). J Med Assoc Thai 2015;98(2):117-22.

[7] Yogev Y, Melamed N, Bardin R, et al. Pregnancy outcome at extremely advanced maternal age. Am J Obstet Gynecol 2010;203(6):558.e1-7.

[8] Dulitzki M, Soriano D, Schiff E, et al. Effect of very advanced maternal age on pregnancy outcome and rate of cesarean delivery. Obstet Gynecol 1998;92(6):935-9.

[9] Leader J, Bajwa A, Lanes A, et al. The effect of very advanced maternal age on maternal and neonatal outcomes: a systematic review. J Obstet Gynaecol Can 2018;40(9):1208-18.

[10] Lean SC, Derricott H, Jones RL, et al. Advanced maternal age and adverse pregnancy outcomes: a systematic review and meta-analysis. PLoS One 2017;12(10):e0186287.

[11] Martinelli KG, Garcia EM, Santos Neto ETD, et al. Advanced maternal age and its association with placenta praevia and placental abruption: a meta-analysis. Cad Saude Publica 2018;34(2):e00206116.

[12] Carolan M, Frankowska D. Advanced maternal age and adverse perinatal outcome: a review of the evidence. Midwifery 2011;27(6):793-801.

[13] Bayrampour H, Heaman M. Advanced maternal age and the risk of cesarean birth: a systematic review. Birth 2010;37(3):219-26.

[14] Huang L, Sauve R, Birkett N, et al. Maternal age and risk of stillbirth: a systematic review. CMAJ 2008;178(2):165-72.

[15] Hypertension in pregnancy. Report of the American College of Obstetricians and Gynecologists' task force on hypertension in pregnancy. Obstet Gynecol 2013;122(5):1122-31.

[16] Sibai BM, Ewell M, Levine RJ, et al. Risk factors associated with preeclampsia in healthy nulliparous women. The Calcium for Preeclampsia Prevention (CPEP) Study Group. Am J Obstet Gynecol 1997;177(5):1003-10.

[17] Duckitt K, Harrington D. Risk factors for pre-eclampsia at antenatal booking: systematic review of controlled studies. BMJ 2005;330(7491):565.

[18] Lawoyin TO, Ani F. Epidemiologic aspects of preeclampsia in Saudi Arabia. East Afr Med J 1996;73(6):4046.
[19] Al-Ghamdi SM, Al-Harbi AS, Khalil A, et al. Hypertensive disorders of pregnancy: prevalence, classification and adverse outcomes in northwestern Saudi Arabia. Ann Saudi Med 1999;19(6):557-60.

[20] Al-Mulhim AA, Abu-Heija A, Al-Jamma F, et al. Preeclampsia: maternal risk factors and perinatal outcome. Foetal Diagn Ther 2003;18(4):275-80.

[21] Sobande AA, Eskandar M, Bahar A, et al. Severe preeclampsia and eclampsia in Abha, the south west region of Saudi Arabia. J Obstet Gynaecol 2007;27(2):150-4.

[22] Wahabi H, Fayed A, Esmaeil S, et al. Riyadh mother and baby multicenter cohort study: the cohort profile. PLoS One 2016;11(3):e0150297.

[23] Subki AH, Algethami MR, Baabdullah WM, et al. Prevalence, risk factors, and foetal and maternal outcomes of hypertensive disorders of pregnancy: a retrospective study in western Saudi Arabia. Oman Med J 2018;33(5):409-15.

[24] Brown MA, Lindheimer MD, de Swiet M, et al. The classification and diagnosis of the hypertensive disorders of pregnancy: statement from the International Society for the Study of Hypertension in Pregnancy (ISSHP). Hypertens Pregnancy 2001;20(1):IX-XIV.

[25] Lai C, Coulter SA, Woodruff A. Hypertension and pregnancy. Tex Heart Inst J 2017;44(5):350-1.

[26] Karumanchi SA. Angiogenic factors in preeclampsia: from diagnosis to therapy. Hypertension 2016;67(6):1072-9.

[27] Lisonkova S, Joseph KS. Incidence of preeclampsia: risk factors and outcomes associated with early- versus lateonset disease. Am J Obstet Gynecol 2013;209(6):544.e1.e12.

[28] Abalos E, Cuesta C, Grosso AL, et al. Global and regional estimates of preeclampsia and eclampsia: a systematic review. Eur J Obstet Gynecol Reprod Biol 2013;170(1):17.

[29] Sheen JJ, Wright JD, Goffman D, et al. Maternal age and risk for adverse outcomes. Am J Obstet Gynecol 2018;219(4):390.e1-.e15.

[30] Kahveci B, Melekoglu R, Evruke IC, et al. The effect of advanced maternal age on perinatal outcomes in nulliparous singleton pregnancies. BMC Pregnancy Childbirth 2018;18(1):343. 